\title{
PENGARUH PENYETELAN SKALA SHEDDING TIME TERHADAP J UMLAH WEFT STOP PADA AIR JET LOOM
}

\author{
THE EFFECT OF SHEDDING TIME SCALE SETTING ON THE NUMBER OF \\ WEFT STOP IN AIR JET LOOM
}

\section{Ervin Hudaya ${ }^{1}$, Sajinu AP. ${ }^{2}$ dan Deni Sukendar ${ }^{3}$}

1. Mahasiswa Jurusan Teknik Tekstil Politeknik STTT Bandung

2. Staf Pengajar Politeknik STTT Bandung

3. Staf Pengajar Politeknik STTT Bandung

\begin{abstract}
ABSTRAK
Penelitian ini dilakukan untuk mengetahui pengaruh penyetelan Sheding Time terhadap WeftStop dengan cara melakukan penyetelan skala shedding time untuk lima variasi skala yaitu skala $270^{\circ}, 280^{\circ}, 290^{\circ}, 300^{\circ}$ dan $310^{\circ}$. Dari hasil penelitian yang telah dilakukan dapat disimpulkan bahwa penyetelan shedding time berpengaruh terhadap jumlah weft stop pada mesin AJ L. Memperlambat skala shedding sampai skala tertentu dapat menghasilkan weft stop yang rendah. Apabila telah lewat dari skala tersebut maka weft stop akan kembali naik. Penyetelan skala shedding time untuk pembuatan kain twill 3/1 menggunakan mesin tenun AJ L Tsudakoma ZAX 9100 adalah skala $290^{\circ}$.
\end{abstract}

Kata kunci: Sheding-time, weft-stop

\begin{abstract}
This study was conducted to determine the effect of Sheding Time adjustment to Weft Stop by performing shedding time scale adjustment for five scale variations ie $270^{\circ}, 280^{\circ}, 290^{\circ}, 300^{\circ}$ and $310^{\circ}$ scale. From the results of research that has been done can be concluded that the shedding time adjustment effect on the number of weft stop on the machine AJ L. Slow shedding up to a certain scale can produce a low weft stop. When it has passed from the scale then weft stop will go up again. Shedding time scale adjustment for making 3/1 twill fabric using AJ L Tsudakoma ZAX 9100 weaving machine is $290^{\circ}$ scale
\end{abstract}

Keywords: Sheding-time, weft-stop 


\section{PENDAhUluan}

Weft stop atau berhentinya proses pertenunan akibat jalannya benang pakan pada mesin tenun air jet loom di PT "X" melebihi standar perusahaan. Weft stop tersebut rata-rata sebanyak 20 kali dalam satu hari (3 shift), sedangkan standarnya adalah rata-rata 16 kali per hari. Jumlah kegagalan peluncuran pakan yang melebihi standar dapat menimbulkan permasalahan pada proses produksi kain grey serta efisiensi produksi. Atas dasar itu perlu ada langkah tindak lanjut untuk mengetahui faktor yang mempengaruhi terjadinya hal ini serta upaya yang harus dilakukan agar jumlah weft stop dapat berkurang sehingga proses produksi dapat berjalan sesuai rencana dan efisiensi dapat meningkat.

Pengaturan skala shedding time yang kurang tepat diduga menjadi penyebab banyak terjadinya kegagalan peluncuran pakan di Departemen Weaving PT "X". Oleh karena itu diperlukan penelitian mengenai skala shedding time berapa yang paling optimum sehingga potensi kegagalan peluncuran pakannya sesuai standar. Penelitian ini dimaksudkan untuk mengetahui pengaruh penyetelan shedding time terhadap jumlah weft stop pada mesin air jet loom, sedangkan tujuan dari penelitian ini adalah mengetahui skala shedding time yang optimal untuk mengurangi weft stop di mesin air jet loom loom.

Proses pertenunan dapat terjadi akibat adanya benang lusi dan benang pakan yang saling menyilang satu sama lain sehingga membentuk anyaman tertentu (Teknologi pertenunan, 1973 p.13). Untuk mendapatkan hasil pertenunan yang maksimal tentunya dibutuhkan gerakan pokok pertenunan yang baik pula, serta penyetelan mesin yang sesuai. Pengaturan shedding time yang kurang tepat mengakibatkan seringnya kegagalan peluncuran benang pakan (weft insertion) pada mesin tenun air jet loom yang dideteksi oleh peralatan weft stop motion (peralatan otomatis berhenti pakan) .

Gerakan menghentikan mesin ketika terjadi kegagalan peluncuran pakan pada mesin air jet loom menggunakan sistem elektronik, selain sangat sensitif, mudah perawatan dan mudah pengoperasiannya, namun mahal harga suku cadangnya. Sistem yang ada kadang berbeda, tergantung dari model media peluncuran benang pakan dan merek mesin tenunnya.

Faktor yang menyebabkan kegagalan dalam peluncuran benang pakan yaitu karena terhalang oleh benang-benang lusi disekitar mulut lusi atau mulut lusi tidak bersih. Mulut lusi adalah rongga yang terbentuk karena adanya gerakan benang lusi naik/turun sebelum peluncuran benang pakan.

Pembukaan mulut lusi adalah proses memisahkan lapisan benang-benang lusi menjadi dua bagian ke atas dan ke bawah, sehingga terbentuk rongga atau sudut dan benang pakan disisipkan ke dalamnya. Menurut Liek Soeparlie, dkk di dalam bukunya (Teknologi Pertenunan, 1973 p 13) mengemukakan bahwa "rongga yang terbentuk harus bersih, sebab jika tidak bersih akan mengganggu peluncuran teropong (pakan)".

Peluncuran benang pakan melintasi mulut lusi harus diusahakan sebaik mungkin agar benang pakan tersebut berhasil mencapai pinggir kain. Benang pakan tersebut diusahakan agar jangan sampai menabrak benang lusi yang dapat mengakibatkan benang pakan tersebut tidak dapat mencapai pinggir kain.

Kegagalan peluncuran benang pakan yang dimaksud dalam penelitian ini adalah keadaan dimana benang pakan tidak dapat mencapai pinggir kain karena disebabkan benang pakan tersebut menabrak benang lusi di daerah mulut lusi.

Bila tertutupnya mulut lusi diperlambat, maka kemungkinan pakan yang menabrak tersebut tidak terjadi dan sampai ke pinggir kain. Range (rentang waktu) mulut lusi membuka dan menutup sudah pasti (tetap) $180^{\circ}$ karena menggunakan cam positif. Bila memperlambat saat penutupan berarti memperlambat pula pembukaannya. Begitupun sebaliknya, jika penutupan dipercepat, maka pembukaan pun berarti dipercepat. Gambar 1. di bawah ini memperlihatkan tahapan selama satu putaran mesin pada peluncuran benang pakan menggunakan hembusan udara. Diketahui pembukaan mulut lusi adalah sebesar $90^{\circ}$ dan penutupan mulut lusi sebesar $270^{\circ}$. 


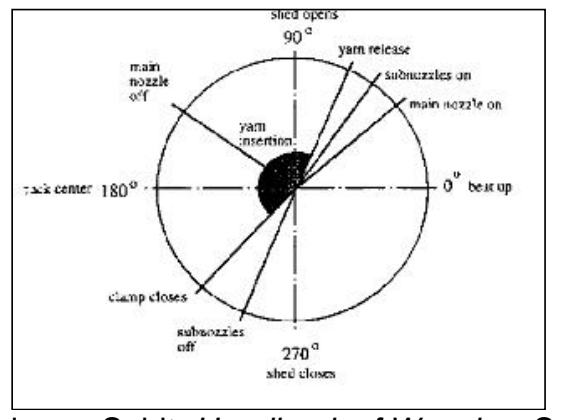

Sumber : Adanur, Sabit, Handbook of Weaving, Sulzer, halaman 177.

Gambar 1. Typical Timing Diagram Mesin Tenun Air J et dengan Multi Nozzle dan Sisir Berprofil Shedding time

Gambar 1. Typical Timing Diagram Mesin Tenun Air J et dengan Multi Nozzle dan Sisir Berprofil Shedding time memiliki skala yang dapat diubah secara manual, dimana perubahan skala akan berimbas pada perubahan kecepatan pembukaan dan penutupan mulut lusi. Dari gambar diagram diatas dapat dilihat jika merubah skala ke shedding ke angka yang lebih kecil maka pembukaan mulut lusi akan terlalu dekat dengan yarn release (peluncuran pakan). Sementara jika skala diperbesar walaupun waktu peluncuran pakan semakin kecil tetapi masih ada sub nozzle yang masih aktif dan bisa menghantarkan benang pakan sampai ke ujung kain.

Pada saat shedding, jika skala shedding terlalu kecil, maka kemungkinan pada saat pakan diluncurkan, mulut lusi di bagian ujung kain akan menutup sebelum pakan tiba, sehingga memungkinkan terjadinya kegagalan peluncuran pakan. Sebaliknya apabila skala shedding terlalu besar maka kemungkinan pada saat pakan diluncurkan, mulut lusi di bagian awal kain kemungkinan masih belum terbuka maksimal, sehingga memungkinkan terjadinya kegagalan peluncuran pakan.
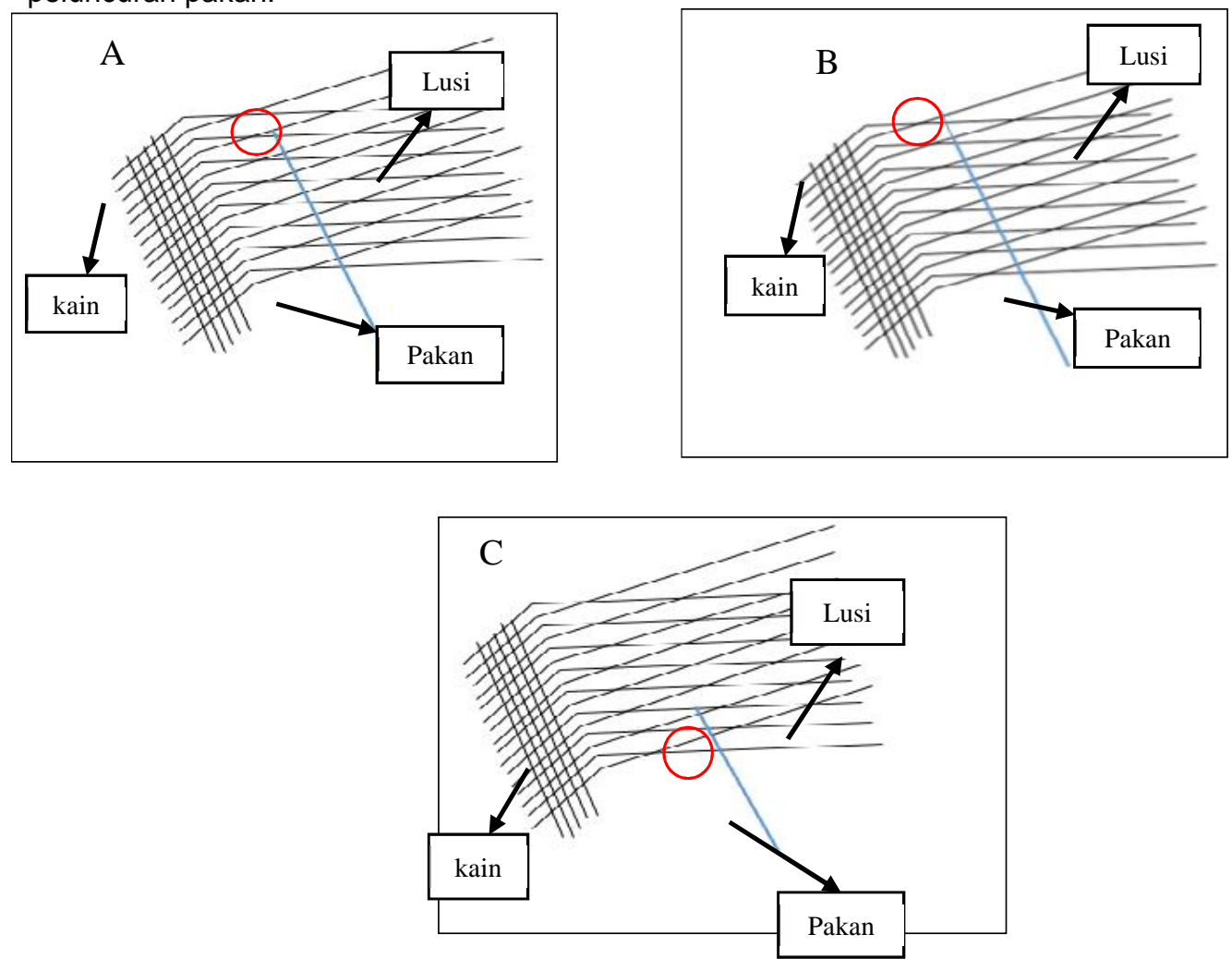

Gambar 2. Mulut Lusi dengan Shedding time Terlalu Cepat (A) Shedding time Normal (B) Shedding time Terlalu Lambat $(\mathrm{C})$ 
Pada gambar A dapat dilihat bahwa benang pakan menabrak mulut lusi sebelum tiba di ujung kain dikarenakan kecepatan shedding time yang terlalu cepat. Pada gambar B dapat dilihat bahwa benang pakan dapat tiba pada ujung kain dikarenakan kecepatan shedding time tepat. Pada gambar $C$ dapat dilihat bahwa benang pakan menabrak mulut lusi di bagian awal kain dikarenakan kecepatan shedding time yang terlalu lambat. Dari pemaparan dugaan diatas, yang perlu dilakukan adalah mencari dan menguji pada skala berapa jumlah weft stop ini terjadi paling sedikit.

\section{METODA PENELITIAN}

Penelitian ini dilakukan dengan metode empiris yang percobaanya dilakukan pada bulan Maret 2017 di PT. "X" dengan menggunakan mesin dan bahan sebagai berikut :

\subsection{Spesifikasi Mesin Tenun}

Mesin tenun yang digunakan sebagai objek penelitian adalah mesin tenun dengan spesifikasi sebagai berikut :

$\begin{array}{lll}\text { 1. } & \text { Merek } & : \text { Tsudakoma } \\ \text { 2. } & \text { Tipe } & : \text { ZAX } 9100 \\ \text { 3. } & \text { Buatan } & : \text { Jepang } \\ \text { 4. } & \text { Tahun } & : 2011 \\ \text { 5. } & \text { Nomor mesin } & : \text { K-03 } \\ \text { 6. } & \text { Cam box } & : \text { Staubli tipe } 1661 \\ \text { 7. } & \text { Jumlah kamran } & : 6 \\ \text { 8. } & \text { Rpm maksimal } & : 1000 \\ \text { 9. } & \text { Pembentuk mulut lusi } & : \text { Cam positif }\end{array}$

\subsection{Konstruksi Kain}

Kain tenun yang dijadikan objek pengamatan oleh penulis adalah kain tenun dengan spesifikasi sebagai berikut :

$\begin{array}{lll}\text { 1. } & \text { Kode kain } & : \text { ZPC } \\ \text { 2. } & \text { Benang lusi } & : \mathrm{SBT} \mathrm{Ne} \mathrm{N}_{1} 30 / 1 \mathrm{PE} \text { atau polyester } \\ \text { 3. } & \text { Benang pakan } & : \mathrm{BTR} \mathrm{Ne}_{1} 20 / 1 \text { Combed atau cotton } \\ \text { 4. } & \text { Jenis anyaman } & : \text { Twill } 3 / 1 \\ \text { 5. } & \text { Tetal lusi } & : 128 \mathrm{hl} / \mathrm{inchi} \\ \text { 6. } & \text { Tetal pakan } & : 50 \mathrm{hl} / \mathrm{inchi} \\ \text { 7. } & \text { Lebar kain } & : 161 \mathrm{~cm}\end{array}$

\section{HASIL DAN PEMBAHASAN}

\subsection{Hasil Pengujian}

Berikut dibawah ini data hasil penelitian dari penyetelan skala shedding time yang di aplikasikan pada satu buah mesin saja dengan settingan mesin yang tidak berubah. 
Tabel 1. Hasil Penelitian Jumlah Kejadian Weft Stop dari 5 Variasi Skala Shedding time.

Data weft stop

\begin{tabular}{cccccc}
\hline $\begin{array}{c}\text { Penguji } \\
\text { an }\end{array}$ & skala & skala & skala & skala & skala \\
\hline 1 & $270^{\circ}$ & $\mathbf{2 8 0}^{\circ}$ & $\mathbf{2 9 0}^{\circ}$ & $\mathbf{3 0 0}^{\circ}$ & $\mathbf{3 1 0 ^ { 0 }}$ \\
\hline 2 & 25 & 18 & 14 & 16 & 22 \\
3 & 23 & 21 & 18 & 21 & 19 \\
4 & 25 & 25 & 12 & 19 & 21 \\
5 & 25 & 23 & 17 & 23 & 25 \\
6 & 28 & 20 & 12 & 16 & 27 \\
7 & 20 & 21 & 11 & 16 & 22 \\
8 & 25 & 21 & 14 & 20 & 24 \\
9 & 23 & 19 & 13 & 19 & 26 \\
10 & 25 & 22 & 16 & 20 & 21 \\
$\bar{X} \approx$ & 24,6 & 20,9 & 14,3 & 18,9 & 23,0 \\
\hline
\end{tabular}

Perhitungan statistik pengaruh penyetelan vasiasi skala shed close time terhadap jumlah weft stop setiap 1 shift atau 8 jam pada skala $270^{\circ}, 280^{\circ}, 290^{\circ}, 300^{\circ}$ dan $310^{\circ}$ didapatkan seperti berikut :

\subsection{Pengolahan Data}

Tabel 2. Pengolahan Data Pengamatan Weft Stop

\begin{tabular}{|c|c|c|c|c|c|}
\hline \multirow{2}{*}{ Parameter } & \multicolumn{5}{|c|}{ Penyetelan skala shedding time } \\
\hline & $270^{0}$ & $280^{\circ}$ & $290^{\circ}$ & $300^{\circ}$ & $310^{0}$ \\
\hline $\mathrm{N}$ & 10 & 10 & 10 & 10 & 10 \\
\hline$\sum$ & 246 & 209 & 143 & 189 & 230 \\
\hline $\bar{X}$ & 24,6 & 20,9 & 14,3 & 18,9 & 23,0 \\
\hline $\mathrm{s}$ & 2,22 & 2,07 & 2,35 & 2,33 & 2,49 \\
\hline Cv & $9,02 \%$ & $9,94 \%$ & $16,43 \%$ & $12,32 \%$ & $10,82 \%$ \\
\hline
\end{tabular}

Keterangan :

1. $\sum=$ Jumlah weft stop yang disebabkan oleh putus pakan.

2. $\bar{X}=$ Rata-rata weft stop per-shift.

\subsection{Pembahasan}

\subsubsection{Perbedaan Penyetelan Shedding dan Weft Insertion pada Mesin Tenun Air J et Loom dan Mesin Tenun Shuttle}

Gerakan yang mempengaruhi kegagalan peluncuran pakan pada mesin tenun ada dua. Pertama gerakan pembukaan mulut lusi (shedding) dan yang kedua gerakan peluncuran pakan (weft insertion). Kedua gerakan tersebut harus menemukan kesesuaian antara satu dan yang lainnya agar didapatkan waktu yang tepat untuk pakan meluncur sempurna sampai ke ujung kain. 
Pada mesin tenun air jet loom waktu peluncuran pakan telah memiliki penyetelan yang diatur secara otomatis pada mesin. Oleh karena itu untuk menyesuaikan antara gerakan shedding dan weft insertion dilakukan penyetelan shedding time yang sesuai antara keduanya. Untuk mementukan penyetelan skala tersebut tentunya berpatokan pada timing diagram mesin tenun air jet loom.

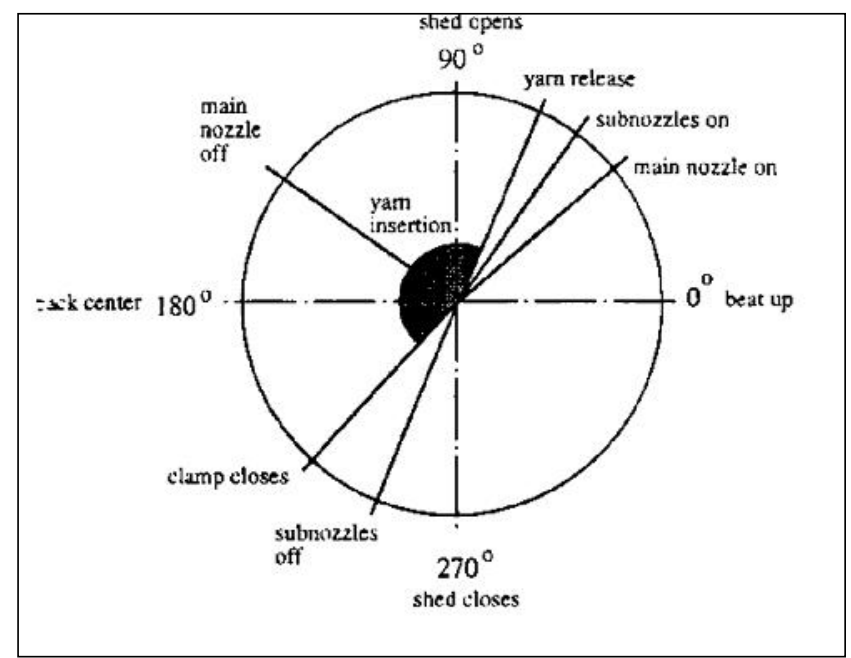

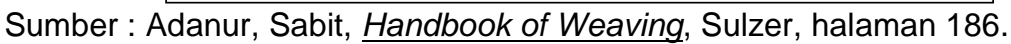

Gambar 3. Typical Timing Diagram Mesin Tenun Air J et dengan Multi Nozzle dan Sisir Berprofil

Dari gambar timing diagram di halaman 31 dapat dilihat bahwa peluncuran pakan dimulai pada skala sekitar $60^{\circ}$ sampai dengan $230^{\circ}$. Secara mekanis jika skala shedding time diturunkan atau dipercepat pergerakannya maka jarak antara waktu peluncuran pakan dan pembukaan mulut lusi akan semakin kecil. Jika skala dirubah $30^{\circ}$ lebih cepat maka peluncuran benang pakan akan terjadi bersamaan dengan pembukaan mulut lusi. Sementara jika memperbesar skala shedding time atau memperlambat pergerakan shedding, waktu peluncuran pakan akan berkurang, namun ketika peluncuran berhenti pada skala $230^{\circ}$ masih ada sub nozzle yang meneruskan pergerakan benang pakan tersebut. Jadi secara mekanis memperlambat skala shedding time merupakan hal yang paling masuk akal dalam penyelesaian masalah gagalnya benang pakan mencapai ujung kain.

Pada mesin tenun shuttle justru kebalikan dari mesin air jet loom dimana gerakan pembukaan mulut lusi kedudukannya tetap. Untuk menyesuaikan antara shedding dan weft insertion dilakukan penyetelan picking atau kekerasan pukulan dimana kekerasan pukulan tersebut akan menentukan kecepatan peluncuran pakan yang sesuai antara keduanya.

\subsubsection{Pengaruh Skala Shedding Time Terhadap Weft Stop}

Pada proses peluncuran benang pakan dengan menggunakan mesin tenun air jet, banyaknya terjadi weft stop yang salah satunya disebabkan oleh ketepatan waktu peluncuran pakan yang berhubungan dengan setelan skala shedding time yang digunakan. Mengingat waktu pembukaan mulut lusi berbanding lurus dengan penutupan mulut lusi maka pada saat peluncuran benang pakan, jika skala shedding time tidak tepat dapat mengakibatkan benang pakan putus akibat menabrak mulut lusi, sehingga hal itu dapat menyebabkan kegagalan proses peluncuran pakan.

Semakin besar skala shedding time yang digunakan maka akan semakin lambat pembukaan mulut lusi dan penutupan mulut lusi juga ikut melambat. Begitu pula sebaliknya, semakin kecil skala shedding time yang digunakan maka akan semakin cepat pembukaan mulut lusi dan penutupan mulut lusi juga ikut cepat.

Jika skala shedding digunakan terlalu kecil atau terlalu besar maka kemungkinan benang pakan yang diluncurkan menabrak benang lusi akan relatif besar sehingga dibutuhkan skala yang paling sesuai waktu pembukaan dan penutupan mulut lusinya. Hal ini sesuai dengan pendapat Giovani 
Castelli, dkk dalam bukunya berjudul Weaving yang mengatakan bahwa "mulut lusi harus terbuka lebar supaya penyisipan pakan dapat berjalan dengan lancar". Untuk meminimalisir terjadinya weft stop akibat pakan tidak sampai karena kecepatan pembukaan dan penutupan mulut lusi yang kurang tepat tinggi, maka setelan skala shedding time harus disesuaikan dengan jenis mesin yang digunakan.

Dari percobaan yang telah dilakukan, didapatkan hasil dari pengaruh variasi skala shedding time terhadap weft stop per shift yang dapat dilihat pada Gambar 4.2 di bawah ini.

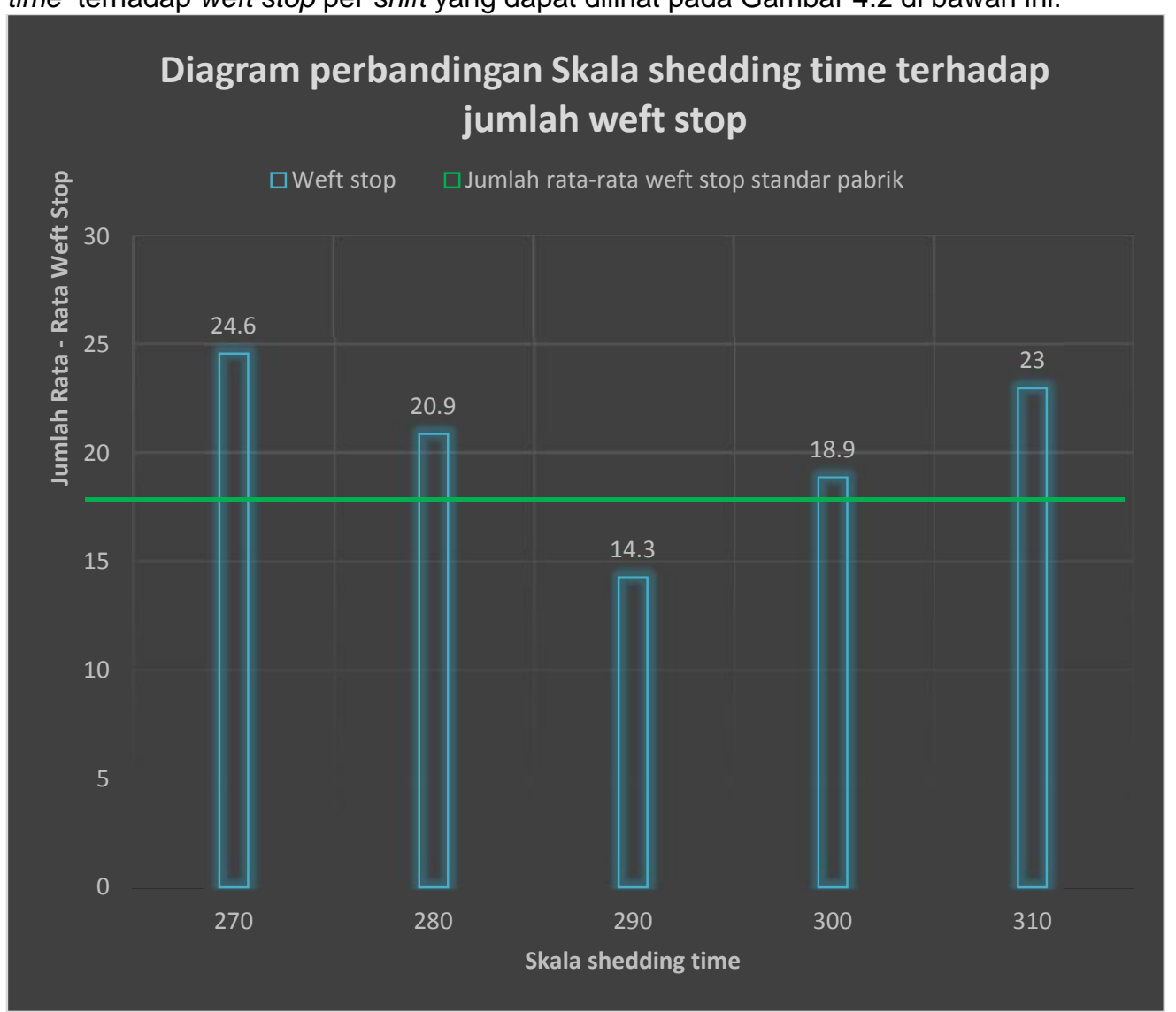

Keterangan :

Gambar 4. Grafik Rata-Rata Weft S top per Shift (8 Jam)

$=$ Jumlah rata-rata weft stop standar pabrik ( 16 kali per shift )

Adapun penjelasan mengenai grafik rata-rata weft stop per shift (8 jam) pada gambar 4 . sebagai berikut: 
1. Shedding time skala $270^{\circ}$

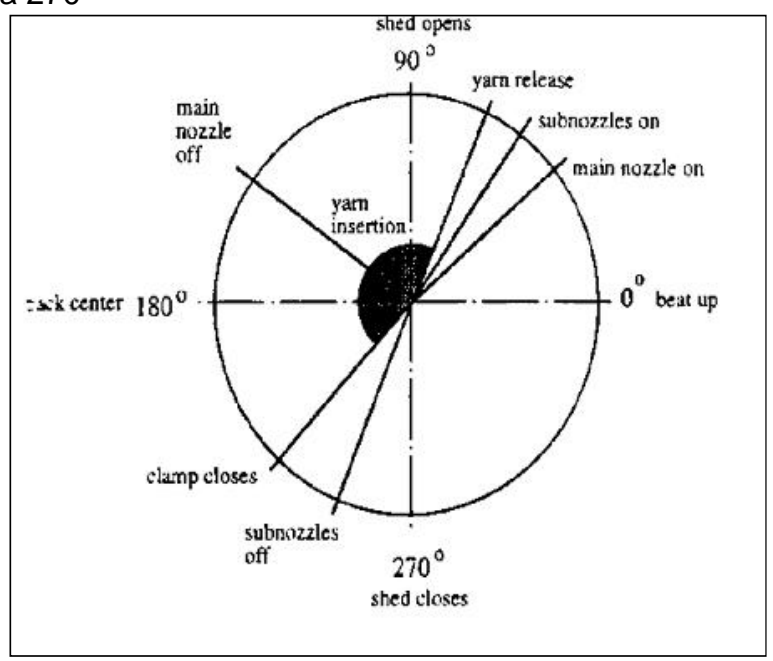

Gambar 5. Typical Timing Diagram Mesin Tenun Air J et dengan Shedding Time Terlalu Kecil

Pada penyetelan Shedding time skala $270^{\circ}$, tingkat rata-rata weft stop per shift (8 jam) yang terjadi merupakan tingkat rata-rata tertinggi dari masing-masing setelan shedding time yang digunakan, yakni skala $270^{\circ}=$ weft stops 24,6 per shift. Hal tersebut terjadi dikarenakan kecepatan pembukaan dan penutupan mulut lusi yang juga masih belum sesuai. Kemungkinan pada saat benang pakan diluncurkan, pembukaan mulut lusi sudah terbuka dan benang pakan dapat meluncur, namun ketika akan mencapai ujung kain, penutupan mulut lusi terjadi terlalu cepat sehingga mengakibatkan benang pakan menabrak mulut lusi di bagian menjelang ujung kain.

2. Shedding time skala $280^{\circ}$

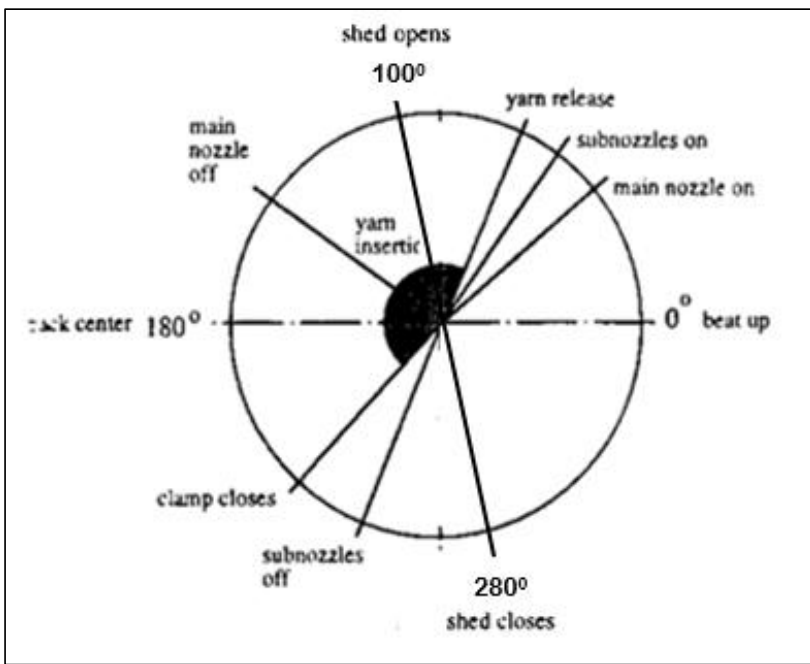

Gambar 6. Typical Timing Diagram Mesin Tenun Air J et dengan Shedding Time Terlalu Kecil

Pada penyetelan Shedding time skala $280^{\circ}$, tingkat rata-rata weft stop per shift (8 jam) yang terjadi merupakan tingkat rata-rata tertinggi ke tiga dari masing-masing setelan shedding time yang digunakan, yakni skala $280^{\circ}=$ weft stops 24,6 per shift. Hal tersebut terjadi dikarenakan kecepatan pembukaan dan penutupan mulut lusi yang juga masih belum sesuai. Kemungkinan pada saat benang pakan diluncurkan, pembukaan mulut lusi sudah terbuka dan benang pakan 
dapat meluncur, namun ketika akan mencapai ujung kain, penutupan mulut lusi terjadi terlalu cepat sehingga mengakibatkan benang pakan menabrak mulut lusi di bagian tengah-tengah menjelang ujung kain.

\section{Shedding time skala $290^{\circ}$}

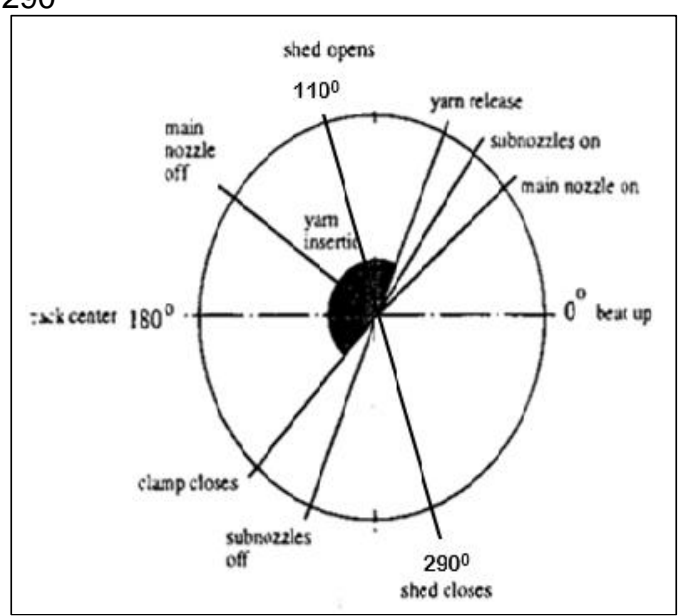

Gambar 7. Typical Timing Diagram Mesin Tenun Air J et dengan Shedding Time Tepat

Pada penyetelan Shedding time skala $290^{\circ}$, tingkat rata-rata weft stop per shift (8 jam) yang terjadi merupakan tingkat rata-rata terendah dari masing-masing setelan shedding time yang digunakan, yakni skala $290^{\circ}=$ weft stops 14,3 per shift. Hal tersebut terjadi dikarenakan kecepatan pembukaan dan penutupan mulut lusi yang sudah sesuai. Kemungkinan pada saat benang pakan diluncurkan, pembukaan mulut lusi sudah terbuka sempurna sehingga benang pakan dapat meluncur mencapai ujung kain tanpa menabrak mulut lusi.

\section{Shedding time skala $300^{\circ}$}

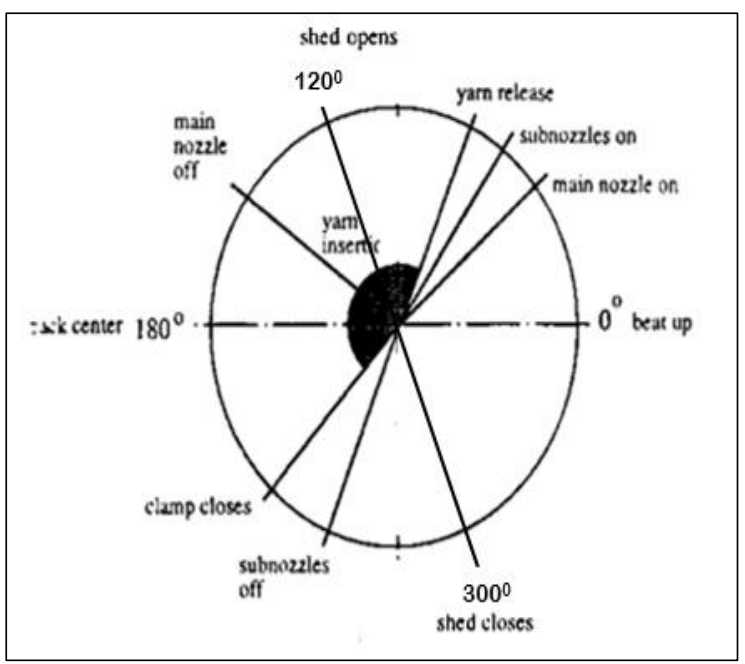

Gambar 8. Typical Timing Diagram Mesin Tenun Air J et dengan Shedding Time Terlalu Terlalu Besar

Pada penyetelan Shedding time skala $300^{\circ}$, tingkat rata-rata weft stop per shift (8 jam) yang terjadi merupakan tingkat rata-rata tertinggi ke empat dari masing-masing setelan shedding time yang digunakan, yakni skala $300^{\circ}=$ weft stops 24,6 per shift. Hal tersebut terjadi dikarenakan kecepatan pembukaan dan penutupan mulut lusi yang juga masih belum sesuai. Kemungkinan pada saat benang pakan diluncurkan, pembukaan mulut lusi masih belum terbuka sempurna 
sehingga mengakibatkan benang pakan menabrak mulut lusi di bagian awal menjelang tengahtengah kain.

5. Shedding time skala $310^{\circ}$

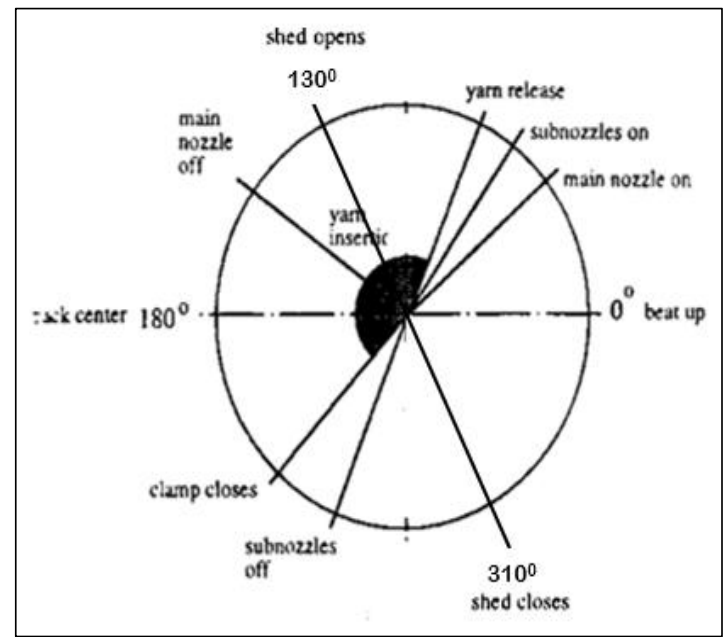

Gambar 9. Typical Timing Diagram Mesin Tenun Air J et dengan Shedding Time Terlalu Terlalu Besar

Pada penyetelan Shedding time skala $310^{\circ}$, tingkat rata-rata weft stop per shift (8 jam) yang terjadi merupakan tingkat rata-rata tertinggi dari masing-masing setelan shedding time yang digunakan, yakni skala $310^{\circ}=$ weft stops 24,6 per shift. Hal tersebut terjadi dikarenakan kecepatan pembukaan dan penutupan mulut lusi yang terlalu lambat. Kemungkinan pada saat benang pakan diluncurkan, pembukaan mulut lusi belum terbuka sempurna sehingga mengakibatkan benang pakan menabrak mulut lusi di bagian awal kain.

Hasil akhir dari pembahasan yang diperoleh dari data rata-rata weft stop per shift (8 Jam) dan data rata-rata effisiensi mesin per shift ( $8 \mathrm{Jam}$ ), dapat diketahui bahwa skala shedding time $290^{\circ}$ merupakan skala yang paling tepat untuk diaplikasikan pada mesin Tenun Air J et Loom Tsudakoma ZAX 9100. Pada skala tersebut menghasilkan jumlah weft stop dan effisiensi mesin yang sesuai dengan standar perusahaan. 


\section{KESIMPULAN}

Berdasarkan hasil pengamatan, pengambilan data dan hasil diskusi dapat ditarik kesimpulan sebagai berikut :

1. Penyetelan shedding time berpengaruh terhadap jumlah weft stop pada mesin AJL. Memperlambat skala shedding sampai dengan skala tertentu dapat menghasilkan weft stop yang rendah. Apabila telah lewat dari skala tersebut maka weft stop akan kembali naik.

2. Pada proses pembuatan kain twill $3 / 1$ menggunakan mesin tenun air jet loom Tsudakoma ZAX 9100, penyetelan shedding time yang optimal yaitu pada skala $290^{\circ}$. 


\section{DAFTAR PUSTAKA}

1. Adanur, Sabit. 2001. Handbook of Weaving. Technomic Publishing Company, Pannsylvania, USA.

2. Giovani Castelli, Salvatore Maietta. Giuseppe Sigrisi. Ivo Matteo Slaviero. 2000. Weaving. Fondazione Acimit, Italian Association of Textile Machinery Producers Moral Body.

3. Liek Soeparli, Dachlan, Okim Djamhir, Ali Sutrisno. 1973. Teknologi Pertenunan. Institut Teknologi Tekstil: Bandung.

4. Onder, Emel. Berkkalp Omer. Weaving Technology II.

5. Sudrajat, Ajat. Laporan Kerja Praktik Lapangan dan Skripsi : Pusaha Mengurangi Jumlah Cacat Karena Putus Lusi Pada Pembuatan Kain T-2325 Di Mesin Tenun Air J et Loom Tsudakoma ZA 203i., Bandung : Sekolah Tinggi Teknologi Tekstil, halaman 2. 2008.

6. http://teddypram.blogspot.co.id/2011/02/praktek-teknologi-pertenunan-modern.html, diakses tanggal 07 Juni 2017 (21.30)

7. Onder, Emel. Berkkalp Omer. Weaving Technology II.

8. __. Buku Pedoman Tugas Akhir (2017), Politeknik STTT Bandung).

9. 1996. Instruction Manual for Tsudakoma Air J et Loom $205 \mathrm{i}$.

10. 2011. Instruction Manual for Tsudakoma Air J et Loom ZAX 9100.

11. ,. 2011 Staubli type 1661, parts catalog. 